\title{
The Skin of Spectral Time in Grisey's Le Noir de l'Étoile
}

The title Tempus Ex Machina originally belongs to Gérard Grisey's first percussion piece, composed between March and August 1979. The composer later gave this title to a talk he delivered at the Darmstadt International Summer Course for New Music in 1980. ${ }^{1}$ This proximity testifies to the relevance of the work to Grisey's theory. Temporality had already been the par excellence area of research for the spectralists - if one admits this label. Grisey defied the label precisely because it underplays the role of temporality: spectralism was applied to a music whose departure point was the 'fascination for extended time and for continuity'. ${ }^{2}$ For Tempus Ex Machina six percussionists are spatially arranged in a circle surrounding the audience, thus the movement of sound in physical space is an integral element of the work's structuring of time. The next piece for percussion was in fact a continuation of the same idea: Le Noir de l'Étoile was composed in 1989-1990 for the same setting, with the addition of magnetic tape and in situ astronomic signals. Tempus was included, unabridged, as the first movement of this work. ${ }^{3}$ Furthermore, as I will show, the same musicaltemporal idea was used in both works for two entire sections in the first and second movements.

As Jérôme Baillet has shown, the temporal organization of Tempus relies on juxtaposition and superposition of processes and not so much on different time scales, as with Grisey's later work; nor it relies on the linearity and continuity of his preceding work, Jour, contre-jour (1978-79), where Grisey achieved the height of what Baillet calls 'spectral time'. ${ }^{4}$ There seems to be in

1 Gérard Grisey, 'Tempus ex machina: A composer's reflections on musical time',Contemporary Music Review 2/1 (1987), 239-75.

2 David Bundler, 'Interview with Gerard Grisey',20 $0^{\text {th }}$-Century Music 3 (1996), <http://www.angelfire.com/music2/davidbundler/grisey.html> (accessed 13 April 2017).

3 ForTempus Ex Machina (but not so for Le Noir de l'Étoile) the percussionists may optionally be laid out linearly on stage, thus maintaining spatiality, although perhaps not so effectively.

4 See Jérôme, Baillet, 'Gérard Grisey', trans. Azizeh Azodi, inGérard Grisey: Catalogue of the works (Paris: Ricordi,1998), 11. More generally, this relates to a change of attitude to pure linearity and continuity in spectral 
Baillet's approach an implicit elaboration of temporality from simply linear, to superposed temporal processes, and finally to multi-layered temporal scales. As I will show, I take the term spectral time to mean something different, so as to testify to the heterogeneity of temporality that Grisey envisioned. As provisional requirements towards a definition of spectral time I would propose that it has to be relative (to the evolution of sounds, to listener's time, etc.), heterogeneous (different kinds of time are involved), and experiential (more than just measurable).

In this article I will provide an interpretation of Grisey's theory of temporality and unpack those ideas by relating them to more general concepts of temporality in French philosophy. I will then focus on Le Noir de l'Étoile in order to analyse the temporal structure of two sections, the opening section and the first section of the second movement. These two sections explore the same temporal issues and seem to be symmetrical in their construction. Further, they exemplify Grisey's main concepts, those of process and object, as well as the concepts I will be discussing in the philosophical section, such as Henri Bergson's duration and Gilles Deleuze's intensity.

\section{Structuring vs. Structure}

In my approach to these two sections of Le Noir de l'Étoile, I will largely follow the methodology recently put forward by Judy Lochhead. ${ }^{5}$ Lochhead identifies a significant lack of music theory and analysis in responding to a paradigm shift in contemporary music since WWII. This shift broadly consists in moving away from a certain epistemological definition of structure, developed by Western music theorists and composers the 1950s and 60s, towards an idea of structure that is not

music. In the early 1980s Tristan Murail and others became aware of a paradox caused by extreme predictability and extreme temporal dilation, which when combined, risk listener perception. See Tristan Murail, 'Target Practice', trans. Joshua Cody, Contemporary Music Review 24/2-3 (2005), 158; and Ingrid Pustijanac, 'Time's arrow in spectral music', Nuove Musiche 1 (2016), 156-57.

5 Judy Lochhead,Reconceiving Structure in Contemporary Music: New Tools in Music Theory and Analysis (New York: Routledge, 2016). 
fixed, but conceived as 'emergent, phenomenal, and malleable'. ${ }^{6}$ Thus, the object of analysis is not the work's 'structure', but its becoming; hence Lochhead's preferred term, structuring (rather than structure). The crucial difference of course between structure and structuring is that of temporality: 'Musical structure is not an unchanging feature of the work but rather something that emerges as a structuring in particular circumstances of listening. Analysis, then, focuses not on 'a structure' but on the emergent structurings - the possibility space — that a musical work generates. ${ }^{7}$ This possibility space includes not only 'the work itself' but may also include the historically and culturally contingent, the work's various interpretations, including any analyses. All these, to the extend they are ongoing, non-definitive, and self-reflexive accounts of musical experience, contribute to the work's becoming: 'Music analysis is a formal process of reflective engagement with musical works with the goal of producing knowledge by proposing new modes of engaging the work and as such contributing to the work's becoming'. ${ }^{8}$

Lochhead's formal approach relies on three interdependent procedures: investigating, mapping, speculating. Although the order mentioned here makes sense, these are not meant to be strictly sequential. Investigating, relates to the experiencing of the work and consists in gathering information and phenomenological evidence relating both to the work's sounding materiality (the experience of listening, either in concert, on recording, or silent sight-reading) and to its cultural or historical context (including its existing interpretations or analyses). Mapping consists in devising tools of orientating oneself around the space of the work (graphs, tables, etc.). Crucially, Lochhead stresses that these are never neutral, as maps never are: mapping serves the analyst's goal and thus affects the analytical findings. Finally, speculating relates to producing an interpretative account of the work. Although this may be thought to follow analysis, speculating also takes place during the other procedures, as - I believe - it informs both investigating and mapping. More concretely,

$6 \quad$ Lochhead,Reconceiving Structure, 7.

7 Lochhead,Reconceiving Structure, 97 (emphases mine).

8 Lochhead,Reconceiving Structure, 77. 
speculating involves employing or producing concepts that serve in interpreting the (possibility space of the) work.

My application here is a good example of overlap between these three procedures. I will provide an overview and interpretation of Grisey's theory of temporality, itself closely related to the work in question (investigating \& speculating); then I will open this up and further reflect against a philosophical background (speculating); and finally, I will provide a mapping of the two aforementioned sections, in which I trace the main temporal concepts developed earlier. This mapping takes the form of graphic transcription, according to dimensions not readily provided by the score. Thus, these graphs will aim at enabling analysis of the emergent structurings of musical time (a central goal of Lochhead's endeavour), by way of a precise mapping of perceivable temporalities.

\section{Grisey and Temporality}

Although Influenced by composers such as Olivier Messiaen, Iannis Xenakis, or Karlheinz Stockhausen, Grisey's theory came as a radical departure from the views of these composers. Their main preoccupations had been either too 'philosophical' for Grisey, or too technical; that is, not relevant to experience as such. The following quote is quite telling of the insistence on perceivable temporality:

Strengthened by an ecology of sounds, spectral music no longer integrates time as an external element imposed upon a sonic material considered as being 'outside time', but instead treats it as a constituent element of sound itself. This music forces itself to make time palpable in the 'impersonable' form of durations; apparently far removed from spoken language, but doubtlessly close to other biological rhythms which we have yet to discover. ${ }^{9}$

9 Gérard Grisey, 'Did you say Spectral?'Contemporary Music Review 19/3 (2000), 2. The term 'outside time' here is a reference to Xenakis's temporal theory, who since the mid 1960s insisted on the primacy of this category. For him, musical structures, such as scales and sequences, exist outside of time due to their inherent order (see Iannis 
In 'Tempus ex machina' Grisey develops his theory on three distinct levels: the skeleton, flesh, and skin of time. Respectively, these refer to the quantitative aspect of musical time, its qualitative aspect, and the subjective time of listening. The skeleton is the domain of analysis by the composer, the level which affords maximum control. The flesh of time, on the other hand, would normally belong to musicians' intuition; but the new methodologies of spectral composition, e.g. microphony, allowed for some degree of control by the composer as well. Finally, the skin of time is the level which eschews any control. In fact, the skin appears to be the contingent, unique experience of time, on which the composer has no say. ${ }^{10}$

Despite such inevitable inadequacy, Grisey develops his theory with an eye to temporal perception, across the first two levels. The criteria for formalizing his approach rely on the perceivable degree of continuity or pre-audibility (borrowed from Abraham Moles' information theory). ${ }^{11}$ He uses various interchangeable terms for this, all of which can be subsumed under two groups:

Xenakis, Formalized Music: Thought and Mathematics in Composition, ed. Sharon Kanach, revised edn. [Stuyvesant, New York: Pendragon Press, 1992], 180-241). Interestingly, the reference to a 'palpable' sense of time, might have influenced Brian Ferneyhough, who was present at Darmstadt in 1980 (see Anne Lebaron and Denys Bouliane, 'Darmstadt 1980', Perspectives of New Music 19/1-2 [1980-1981], 420-41) and in 1988 presented his own theory of temporality there, in a talk titled 'The Tactility of Time' (see Brian Ferneyhough, Collected Writings, ed. James Boros \& Richard Toop (Amsterdam: Harwood Academic Publishers, 1995), 42-50). For a comparative study of Grisey's and Ferneyhough's approach to temporality see Lukas Haselböck, Gérard Grisey: Unhörbares hörbar machen (Freiburg: Rombach Verlag, 2009), 252ff.

10 See Grisey, 'Tempus ex machina', 257ff. Cf.Lebaron and Bouliane, 'Darmstadt 1980', 428-9.

11 SeeGrisey, 'Tempus ex machina', 244. Cf. Luigi Manfrin, 'L'immagine spettrale del suono e l'incarnazione del tempo allo stato puro. La teoria della forma musicale negli scritti di Gérard Grisey’, De Musica VIII (2004), $<$ users.unimi.it/gpiana/dm8/manfrin/grisey.zip> (accessed 13 April 2017), 23ff. 


\begin{tabular}{ll}
\hline Continuity & Discontinuity \\
\hline \hline Predictability (Pre-audibility) & Unpredictability \\
Dynamism & Stasis \\
Periodicity & Aperiodicity \\
\hline \hline
\end{tabular}

In the skeleton Grisey locates five temporal categories which he classifies from order to disorder, that is to say, from predictability to unpredictability: periodic, dynamic (continuous or discontinuous acceleration or deceleration), statistical, and smooth. ${ }^{12}$ The former term suggests maximum predictability, whereas zero predictability indexes the statistical category. Thus, smooth time, Pierre Boulez's term for 'unpulsed', 'amorphous' time, ${ }^{13}$ is beyond unpredictability, suggesting 'rhythmic silence'. ${ }^{14}$ The composer here clearly departs from Boulez, due to an insistence on a phenomenology of temporal consciousness. This is because, as he suggests, the difference between metric and smooth time is not perceptible unless a feeling of periodicity is provided by the music. Similarly, he departs form Messiaen's temporal theory, precisely due its lack of phenomenological concern, the example being non-retrogradable rhythm, which is not necessarily heard as such due to different possible groupings in audition.

While the skeleton of time is controlled by measurable time, the flesh of time, the intuitive aspect of musical time, is more resistant to control. This is the reason, according to Grisey, why this aspect of time has been relatively unacknowledged by compositional theory. The flesh, being 'qualitative', is not accessible by analysis, and Grisey set out to rectify this. The method to approaching the flesh relies on two axes: his relativistic conception of time and his materialist

12 Note that these are not meant to be fixed, but exist in a continuum that may allow for further (sub-)categories.

Neither are they strictly linear, as the 'degree of complexity' is variable and dependant upon several factors, such as musical context, subjective perceptual capacity, etc. (see Grisey, 'Tempus ex machina', 244-5).

13 See Pierre Boulez,Boulez on Music Today, trans. Susan Bradshaw and Richard Rodney Bennett (London: Faber \& Faber, 1971), 85-9.

14 Grisey, 'Tempus ex machina', 244. 
conception of sound. The flesh of time relates to the 'sound material' and to the 'relativity of any temporal structure from the moment a sound materializes it'. ${ }^{15}$ Continuity here relies on the relativity or difference between a sound and its neighbour. This differential logic itself relates to the amount of information provided and perceived as a function of time; when passing from the known to the relatively unknown, that is, to a relatively unpredictable sound, attention is drawn from the global form to the local. Thus, there is some loss in dynamism in favour of stasis. The difference itself between two neighbouring sound events is termed by Grisey the 'density of the present' and indexes the 'speed of time' between events. In extreme situations, this difference can become an event in itself, although this might not be readily determined: "How large can the gap between "A" and "B" be before this gap becomes an entity in itself?'. ${ }^{16}$ The difficulty in approaching such a question lies in the radical complexity that arises from the moment the subjective time of the listener is taken into account.

Grisey made reference to an 'uncertainty principle' in determining sound entities. This uncertainty arises from his conception of object and process. Conceivably, the aforementioned case of transitioning to an unpredictable sound event, if taken to the extreme, so that only local focus is afforded, will contract time to the point of a singular object; whereas the opposite, the timestrethcing of an object will expand time. ${ }^{17}$ We thus see a chiasmus here: an object is a process that has been contracted, whereas a process is a dilated sound object. We could therefore relate an object to excessive information (with respect to time), as this is what would cause time to stop (in other words, our memory would become 'mute' and focus only on the instant); and conversely, we could locate process on the side of extreme predictability. This is a convenient inverse analogy, but one should be aware of its apparent simplicity. As I will show in my analysis of the two sections in Le noir de l'Etoile, a large-scale formal process can be effectuated as a heterogeneous combination of

15 Grisey, 'Tempus ex machina', 258.

16 Lebaron and Bouliane, 'Darmstadt 1980', 428.

17 Grisey, 'Tempus ex machina', 253. 
processes, including the subsuming, but not transforming, of objects into processes. Further, if process is conceived as differential, and to the extent that both process and object are perceived as functions of time, they should both be conceived as differential. Grisey has hinted at such thinking when he wrote that 'it is impossible to think of sounds as defined objects which are mutually interchangeable. They strike me rather as force fields given direction in time'. ${ }^{18}$

\section{Touching the Skin of Time}

There is a clear transition in Grisey's schema, from the level of rigorous formalization (skeleton), to the level of cautious application of actions hitherto intuitive (flesh), and to the outer level of the skin, where the composer may not readily interfere: this is the point of contact between listener and sound. The skin metaphor here is quite apt, as it suggests contact with a material entity. Although himself and other spectralists often referred to the 'depth of sound' with regard to the flesh of time, ${ }^{19}$ as if sound were a hollow in which the listener may enter, Grisey's own materialism suggests that this would be impossible. One may dissect the flesh, but one cannot penetrate it.

I will here borrow a schema by philosopher Jean-Luc Nancy who elaborated on the notion of touch throughout his philosophy, and in relation to music in particular. With a view to introducing the concept of the 'resonant subject', as opposed to a 'philosophical' one, Nancy developed his thinking of sound conceived materialistically, with vibration and timbre being sound's own rhythm and its materiality: 'even a simple monotone sustained contains rhythm and timbre'. ${ }^{20}$ Although

18 Grisey, 'Tempus ex machina', 268. Deleuze elaborates on the concept of theforce-field in his book on Fancis Bacon. See Gilles Deleuze, Francis Bacon: the logic of sensation, trans. Daniel W. Smith (London: Continuum, 2003).

19 See Grisey, 'Tempus ex machina', 268.

20 Jean-Luc Nancy,Listening, trans. Charlotte Mandell (New York: Fordham University Press, 2007$), 40$. Interestingly, in thinking resonance, Nancy employs the term 'acoustic space', an explicit reference to Grisey, 'who explores the realms of sonorities and their amplifications or intensifications' (Nancy, Listening, 71 n.14). 
itself the concept of materiality may be contested, Nancy's necessary condition for it is that of impenetrability. In a materialist world-view, all sensing, including listening, is metonymically transformed to touching: palpating on the external border of matter. Listening is thus conceived as the act of touching sound, or being touch by it, as if the atmospheric vibrations are touching my body, including the membrane of my ears - the eardrums. ${ }^{21}$ Further, for Nancy listening is also to be conceived as 'to stretch the ear', as straining towards a certain meaning. ${ }^{22}$ These two modes of listening take place at the same time, but — crucially — they never fuse: meaning and matter are in contact, but never interpenetrate. Thus, for Nancy, listening (touching, sensing) is in search of meaning, while at the same time touches on the materiality of sound.

I have employed the concept of touch here, as a metonymy of all senses, in order to illustrate the radical complexity of the temporality involved in listening. ${ }^{23}$ The source of such complexity is due to a conception of musical sound as intersensory. ${ }^{24}$ This is true for Nancy and must be thought of in relation to Grisey, as it determines the 'receptivity and physio-psychological state' of the listener. ${ }^{25}$ According to this thinking, music is by definition syn-aesthetic, ${ }^{26}$ and the multiplicity of senses it involves, gives rise to multiple temporalities. Thus, the infinite complexity that Grisey

21 I am thankful to Chris Halliwell for pointing out this in relation to audiometry.

22 Nancy,Listening, 5.

23 Touching itself implies its own temporality (seeNancy, Listening, 8 and 70 n.12)

24 This view is also shared by Lochhead(see Lochhead, Reconceiving Structure, 87).

25 Grisey, 'Tempus ex machina', 273.

26 '[Art] dislocates "common sense" or ordinary synesthesia, or it causes it to touch itself in an infinity of points or zones. Difference proliferates, not only among the major sensorial registers, but across each of them: color, nuance, paste, brilliance, shadow, surface, mass, perspective, contour, gesture, movement, shock, grain, timbre, rhythm, flavor, odor, dispersion, resonance, trait, duction, diction, articulation, play, cut, length, depth, instant, duration, speed, hardness, thickness, vapor, vibration, cast, emanation, penetration, grazing touch, tension, theme and variation, et cetera, that is, multiplied touches ad infinitum' (Jean-Luc Nancy, The Muses [Stanford, Calif.: Stanford University Press, 1996], 22) 
evokes $^{27}$ is not the only obstacle towards theorization. As I have shown, in Nancy's thinking, meaning and matter exist in touch-separation with one another; they are two different 'outsides'. What separates them is a limit, an impenetrable skin, which can be touched, but not penetrated. From the moment one attempts to theorize on musical experience, one finds oneself within the impervious limits of language, abstraction, measurement. Hence Grisey's silence on the skin of time: it can be touched, but this touching cannot be abstracted from sonorous materiality. ${ }^{28}$

\section{Measurable \& Experiential Time}

I propose here to reinterpret this tripartite theoretical schema according to a dualistic one, namely the not uncommon distinction made by several composers and philosophers, between measurable and experiential time. The first two levels largely correspond to these two kinds of time, according to which the skin of time may seem redundant. This is not to suggest that this level is of no importance; to the contrary, as the preceding section has shown, the lack of compositional theory does not imply any lack of significance, but is the result of the complexity and near-impossibility to theorize on subjective temporalities. What I suggest is not the withdrawal of the skin level, but that this is already presumed, more or less explicitly, on the other two levels. Grisey himself insisted on temporal perception already in his analysis of the skeleton and of the flesh. Several composers have developed their temporal theory on the distinction between measurable and experiential time. ${ }^{29}$ In

27 See Grisey, 'Tempus ex machina', $257 \& 273$.

28 Undoubtedly, advancements in cognitivism, psycho-acoustics, and neuroscience, as well as in the sociology and anthropology of sound, have opened up this space. However, as Tristan Murail admitted in his keynote at the 'Spectralisms' conference held at the University of Oxford on 15-16 March 2017, such developments are still at an early stage and cannot be safely relied upon for compositional purposes.

29 Various terms for this distinction include: static/progressive (Messiaen); outside-/inside-time (Xenakis); striated/smooth (Boulez); structure/experience (Stockhausen); chronometric/chronoametric (Carter). An overview of these is provided in Edward Campbell, Music after Deleuze (London: Bloomsbury Academic, 2013), 99-129. For Xenakis see Iannis Xenakis, Kéleütha (Ecrits), ed. Alain Galliari, preface by Benoît Gibson (Paris: L'Arche, 
spite of his warning against dualistic categories as arbitrary (rational/irrational, symmetry/asymmetry, and so on), ${ }^{30}$ Grisey seems to also have relied on a dualistic approach, in two different ways. First, his continua of temporal categories on the skeleton, and of degree of preaudibility on the flesh, rely on a polarity of continuity/discontinuity. Second, the degree of formalisation on each level, relies strongly on the distinction of chronometric/perceptible time: the skeleton relies on a chronometric kind of time, while the flesh assume an experiential kind of time.

Grisey's implicitly dualistic approach was carried out under the parameters set by the criteria of continuity and discontinuity, which may take several forms, across the two levels. On the skeleton, the level of analysis, Grisey's temporal categories take the form of temporal progressions that, as I mentioned, give rise to varying degrees of temporal perception, from the completely periodic (temporal stasis), to the acceleration/deceleration in a more or less continuous way, to random distribution of temporal intervals (a temporal kind of white noise, only effective for short spans of time), and to smooth time (a temporal kind of silence, that may be either perceptual or conceptual). The same criteria operate on the level of the flesh, with the additional parameter of difference. The relative difference of neighbouring sound-events affects the 'density' of time. This difference is varyingly complex if one considers that each sound implies its own temporality in multiple ways: the evolution of its envelope, the nature of its source, its spatial volume and arrangement, its recognizability, its semantic or narrative implications, etc. Thus, neighbouring sound-events amplify this complexity due to the sheer fact of their materialization. Grisey's original vision of a 'liminal' music, a music based on the transitioning between sounds through thresholds, relied on this idea of relative difference. ${ }^{31}$ Such differing is far more complex than the temporal progressions on the skeleton level. To rhythm in the simplified sense of successive temporal

1994), 68.

30 Grisey, 'Tempus ex machina', 244.

31 See Gérard Grisey. 'La musique, le devenir des sons', inAlgorithmus, Klang, Natur: Abkehr vom Materialdenken? (Mainz: Schott, 1984), 16-23. 
intervals, is now added the rhythm of sound itself (its vibration), its timbre (its materiality), density, depth - in short, its experiential, material temporality. When Grisey, on the flesh of time, refers to the degree of pre-audibility, quite clearly he does not refer to a kind of formalized scale of measurable pre-audibility; he actually states that this would depend on 'perceptible time, as opposed to chronometric time'. ${ }^{32}$

The skin of time comprises Grisey's own approach to these two kinds of time. As I will show later, both chronometric and experiential time are always given as a composite and although they are different in many ways, they are interdependent. In short, the skin of time, is what turns this composite of chronometric and experiential time into what we could call spectral time. Thus, if spectral time is a distinct kind of temporality in contemporary music, it is a heterogeneous composite of both measurable and experiential time, with appropriate insistence on its phenomenologically perceivable qualities. ${ }^{33}$ In the following section I will trace these two kinds of temporalities, via the notion of difference in Henri Bergson and Gilles Deleuze, before I relate them to the temporalities involved in Grisey's percussion work.

\section{Duration and Difference}

The distinction between measurable and experiential time is known in philosophy from the early work of Henri Bergson, who put forward the idea that time can be thought as a kind of

32 Grisey, 'Tempus ex machina', 258.

33 I use the term 'phenomenological' in the sense of 'pre-theoretical'. Although the philosophers mentioned in this article share some affinity to properly speaking phenomenology, I do not follow this tradition here. In relation to Gilles Deleuze in particular, James Williams notes that 'Deleuze does not seek universal phenomena though a process of reduction - he seeks universal conditions on the ground of the sensations of individuals' (James Williams, Gilles Deleuze's Difference and Repetition: A Critical Introduction and Guide, 2nd edn [Edinburgh: Edinburgh University Press, 2013], 110). 
homogeneous space, where distances can be measured as temporal intervals. ${ }^{34}$ This kind of time, conceived in its measurable aspect, is accessible by analysis, and this is what I claim to correspond to Grisey's skeleton of time. This is a kind of spatialized time, to the extent that space is thought as homogeneous, the dimension(s) in which things are extended. Things in homogeneous time (or space) can be compared, combined, altered, all according to their difference in degree. I can say that this interval is that many times longer than another, or longer by that much; I can even say that this sound-event is that much later in time in relation to an earlier event, and so on. These are all differences in degree and operate in a homogeneous time/space. No mention is made of the events' qualities, or of different kinds of sound-events.

On the other hand, experiential time, according to Bergson, is heterogeneous. There, things are characterised by differences in kind, rather than in degree. Heterogeneity indicates the multiplicity of different kinds of sound-events and different kinds of associated temporalities. The existence and interaction of multiple different temporalities had always been a central preoccupation for Grisey, who said that 'real musical time is only a place of exchange and coincidence between an infinite number of different times' ${ }^{35}$ This kind of real time is accessible by intuition, and Bergson's term for it is duration. Intuition is used very precisely by Bergson as distinct from intellect (or instinct), ${ }^{36}$ and this distinction is based on temporality; as A. W. Moore notes, 'intuition is a way of knowing nature in its enduring self. Analysis is a way of knowing nature as if it had eventually come to an end'. ${ }^{37}$

Not only measurable time is accessible by analysis, but it is accessible by analysis only; similarly, duration is accessible by intuition only. This is stressed by Gilles Deleuze, who in his

34 See Henri Bergson,Time and free will: an essay on the immediate data of consciousness, trans. F.L. Pogson (Mineola, N.Y.: Dover Publications, 2001).

35 Grisey, 'Tempus ex machina', 274.

36 See Leszek Kolakowski,Bergson (Oxford; New York: Oxford University Press, 1985), 60.

37 A. W. Moore,The evolution of modern metaphysics: Making sense of things (Cambridge; New York: Cambridge University Press, 2012), 414. 
analysis of Bergson's ideas, went as far as to use the term duration for (experiential) time and reserve the term space for measurable time. Bergsonian duration is pure temporality, while chronometric time, a form of space, is not adequate to structure temporal experience (although necessary). Further, Deleuze points out that the notion of difference itself is affected by this distinction. Difference in degree and difference in kind, differ more than just in kind:

It is not enough to say that the difference in kind is between two tendencies, between two directions, between space and duration. [...] It is duration that includes all the qualitative differences, to the point where it is defined as alteration in relation to itself. It is space that only presents differences in degree, to the point where it appears as the schema of an indefinite divisibility. [...] There is therefore no longer any difference in kind between two tendencies, but a difference between the differences in kind that correspond to one tendency and the differences in degree that refer back to the other tendency. ${ }^{38}$

From this Deleuze concludes that 'between the two there are all the degrees of difference' and that 'all the degrees coexist in a single Time' ${ }^{39}$ Experience is always given as a 'composite of space and duration'; ${ }^{40}$ duration, as pure temporality, would not be possible without a 'spatial' aspect. The aforementioned critique of Grisey on the Boulezian concept of smooth time is relevant here: smooth, unpulsed time would not be possible without a feeling of periodicity provided by the music itself. Under the light of duration and space, we see that this is not merely a relativistic approach, but that somehow, pulsed time is a necessary condition for smooth time. ${ }^{41}$ With regard to Le Noir de

38 Gilles Deleuze,Bergsonism (New York: Zone Books, 1991), 92-3.

39 Deleuze,Bergsonism, 93. Cf. Luigi Manfrin, 'L'immagine spettrale del suono e l'incarnazione del tempo allo stato puro. La teoria della forma musicale negli scritti di Gérard Grisey’, 16; and Luigi Manfrin \& Marcello Piras, 'Spettromorfologia, Durata et Differanza: La presenza di Bergson nel pensiero musicale di Gérard Grisey', Rivista Italiana di Musicologia 38/1 (2003), 75-117.

40 Deleuze,Bergsonism, 37.

41 This should not be taken to imply that Boulez's conception consists in a simplistic dualism. As he states, his categories of smooth and striated time depend on 'reciprocal interaction, since time cannot be only smooth or only 
l'Étoile, as I will show, its temporal experience relies, among others, also on the chronometric function of the pulsations that provide a reference for perceivable tempi (this 'spatial' aspect is additional to the physical spatial arrangement of the percussionists, which gives rise to spatial movement). Thus we see that the heterogeneity of duration is not simply due to involving different times, but primarily because of the composite nature of temporal experience, which always involves chronometric time. This composite structure of time corresponds to the heterogeneous and experiential aspects of spectral time that I referred to earlier.

Another important point in the quote of the previous paragraph is that space and duration exist in the form of directions, or tendencies. In Bergson's theory of temporality, the past of duration exists virtually in the form of tendencies, and duration itself consists in the actualization of these tendencies. Further, every actualization creates new tendencies, thus the past of duration constantly grows, which means that the virtual is never completely actualized. ${ }^{42}$ The virtual suggests the aspect of reality that is independent of specific things; it refers to becomings or intensities that may be shared by various actual things. ${ }^{43}$ Thus, the becoming-fast or becoming-slow is an intensity of the virtual aspect of the music that effectuate it. According to Deleuze, 'only that which differs in kind can be said to be pure, but only tendencies differ in kind' ${ }^{44}$ Therefore, although duration is the actualization of the virtual, in Deleuze's account it is related to the latter, as both duration and the virtual are characterised by difference in kind. The following schema provides some examples of concepts in space and in duration: ${ }^{45}$

striated' (Pierre Boulez, Orientations: Collected Writings, ed. Jean-Jacques Nattiez, trans. Martin Cooper [London; Boston: Faber \& Faber, 1986], 87).

42 See Moore,The evolution of modern metaphysics, 414.

43 See Williams,Gilles Deleuze's Difference and Repetition, 7-13.

44 Deleuze,Bergsonism, 22.

45 See Deleuze,Bergsonism, 38. 


\begin{tabular}{ll}
\hline \hline Duration (pure time) & Space (homogeneous time) \\
\hline \hline interiority & exteriority \\
heterogeneity & simultaneity / juxtaposition \\
qualitative discrimination & quantitative differentiation \\
difference in kind & difference in degree \\
continuous and virtual & discontinuous and actual \\
\hline \hline
\end{tabular}

The virtual/actual distinction is not meant to correspond neatly to duration and space, neither to Grisey's categories of the flesh and the skeleton of time. Duration, as actualization of the virtual, is given in a composite experience of time (at the same time virtual and actual). This helps extend and better define Grisey's category of the flesh, as the 'relativity of any temporal structure from the moment a sound materializes it'. As he admitted, the flesh is 'subtler and more nebulous' than the skeleton and the perception of the latter depends on 'the way in which the volumes and weights of the musical flesh are distributed' ${ }^{46}$ If we think the flesh of time in terms of Bergsonian duration, we see that, by way of actualizing virtual tendencies, the flesh of time brings forth differences in kind that exist as tendencies in sound's own materiality and temporality. This actualization is the result of (and results in) the composite experience of musical temporality, which depends also on the skeleton, or homogeneous chronometric time. Thus, both the skeleton and the flesh of time partake of the composite temporal experience viewed as actualization-although there is a clear tendency, in Grisey as in Deleuze, to assign more weight to the flesh and to difference in kind.

\section{Intensities}

We see therefore, that differences in kind exist both in the virtual, and in duration, as the actualization of the virtual. For Deleuze, the idea of difference is primary and should not be thought of in negative or derivative terms; that is, difference is not non-identiy. In his reading of Deleuze, 46 Grisey, 'Tempus ex machina', 257-8. 
Moore points at a special kind of difference that 'slips through Bergson's net' and which is central in my analysis of Grisey's processes in Le Noir. Beyond the spatialized difference in degree, and the pure difference in kind, lies intensive difference, which partakes both of the virtual and of the actual. ${ }^{47}$ Such differences are, for example, differences in frequency, loudness, speed, acceleration, brightness, heat, etc. To the extent that these differences can be measured, they can be represented as differences in degree. However, they do not occupy the same metric space as spatial, extensive differences. As Moore points out, intensive differences 'cannot be measured in their own terms'. ${ }^{48}$ This is because the intensities that make up these differences, are already differential: e.g. frequency or speed are functions of time, acceleration is a function of speed, and so on. As Deleuze said, 'the expression "difference of intensity" is a tautology'. ${ }^{49}$ Thus, if an intensity is differential with respect to $\mathrm{E}-\mathrm{E}^{\prime}, \mathrm{E}$ itself refers to $\mathrm{e}-\mathrm{e}^{\prime}$, e refers to $\varepsilon-\varepsilon$, etc. One way, Moore suggests, to verify this is by considering combining such intensities: combining entities of extensive difference results in aggregate intensity; whereas combining entities of intensive difference results in 'something of an intermediate intensity' ${ }^{50}$ Music is an excellent field to confirm this: combining two frequencies does not yield their sum, but a different kind of sonority; spectral music here being a prime example, with its composition at once of harmony and timbre, or its drawing on electroacoustic techniques (e.g. combination tones - the ombre sonore). With regard to Le Noir's percussive pulsations we can consider each individual pulsation as a different intensity of speed; thus, multiple speeds combine to make up not one single aggregate speed, but a composite perceivable acceleration or deceleration that results from this combination. Thus, for Deleuze, both speed and slowness are intensities and as such are not conceived in complementary or negative terms;

\footnotetext{
47 Moore,The evolution of modern metaphysics, 557.

48 Moore,The evolution of modern metaphysics, 558.

49 Gilles Deleuze,Difference and repetition, trans. Paul Patton (London: Athlone, 1994), 222.

50 Deleuze,Difference and repetition, 558.
} 
combining these two kinds of intensities would not cancel each other out, but produce a composite that, in the context of this study, corresponds to the heterogeneity of spectral time.

\section{Processes, Objects, Intensities}

This section provides an analysis of two sections from Le Noir de l'Étoile. Movement 1, as already mentioned, dates back in 1979 and was originally a standalone work, Tempus Ex Machina. Despite the span of a decade, the two works explore the same musical ideas. Especially the opening sections of movements 1 and 2, rely on the same processes, so much so, that the one seems to comprise the mirror form of the other. Table 1 provides the global form of the work. ${ }^{51}$ In between the three movements there are two 'windows' of live transmission of a pulsar, ${ }^{52}$ which overlap with the subsequent percussion sections.

The purpose of this analysis is not to reconstruct the compositional rationale of these sections, but, following the aforementioned methodology, to locate the emergent structuring of musical time..$^{53}$ This structuring, I hope to show, is based on the composition of processes and objects, that effectively help transform into intensive time what is originally perceived as extensive time. I will provide an overview of the sections before I proceed to more detailed analysis, and finally relate these to the concepts of temporality explored earlier.

Each of sections $1 \mathrm{~A}$ and $2 \mathrm{~A}$ consists in a double tempo canon. Percussionists enter successively at a different tempo marking, each new entry being faster that its preceding one by a

51 This table is based on the published score and on Grisey's own plan as provided in Jean-Pierre Luminet, 'Le Noir de l'étoile: La musique des pulsars', in Le temps de l'écoute: Gérard Grisey, ou la beauté des ombres sonores, ed. Danielle Cohen-Levinas (Paris; Budapest; Torino: L'Harmattan, 2004), 182. Adjustments have been made to fit the score and on certain section labels; the character labels are taken from Grisey's plan.

52 The second of which may be pre-recorded.

53 Bailletprovides the rationale behind and beyond these processes, evidently based on study of pre-compositional materials. See Baillet, Gérard Grisey, 167-176. 
constant difference. The former section effectuates a gradual acceleration of perceivable tempo overall, whereas the latter a deceleration. In terms of formal function, the opening of section $1 \mathrm{~A}$ comprises an effective musical introduction, its slow pulsations setting the tone for the entire work, as if a pulsed time is being born out of nothing. In section $2 \mathrm{~A}$ the percussionists join pulsar Vela in a high-speed tremolo at rhythmic near-unison, before they set off at even higher tempi to initiate a process of deceleration. In both cases, this structuring of musical time is achieved via two looselyrelated canons, one on the idiophones (log drums) and the other on the membranophones (tom toms, Chinese drums, congas, roto toms, boo bams, bongos). However, due to the difference in tempo markings, the first percussionist having the slowest, neither canon is audible at the beginning. As each section progresses, the six double parts gradually converge and the canon starts to emerge. One of the purposes of this analysis is to locate the stages of this emergence.

In some ways the two sections are symmetrically constructed. In section $1 \mathrm{~A}$ the membranophones perform slow regular pulsations that gradually speed up. The wood percussion have short explosive gestures, that interrupt these pulsations and become gradually longer. In $2 \mathrm{~A}$ the wood percussion start with rapid pulsations (measured tremoli) that gradually slow down, nearly reaching the pulsations of the opening $(1 \mathrm{~A})$; the membranes interrupt this process by slow, soft, irregular gestures that become gradually denser. Figures 1 and 2 show the single part of each canon. The $x$-axis of these graphs represents extensive time, whereas the $y$-axis represents perceivable tempi, that is, intensive time. These two conceptions of time correspond to the two concepts of difference explored earlier: extensive time corresponds to measurable, 'spatial' time and to difference in degree (measured in crotchets); while intensive time to intensity which is not metrical but experiential (perceivable tempo or change thereof). In terms of Grisey's theory, these correspond respectively to the skeleton and to the flesh - a dualistic approach that, as I claim, supersedes his original threefold schema. 
In Figures 1 and 2 solid lines represent the pulsations and asterisks represent the gestures that interrupt these pulsations. I take these gestures to be objects, opposing the gradual speeding-up or slowing-down process, on the membranes and idiophones respectively for the two sections. These objects, in keeping with Grisey's conception, are assumed to occupy no time. Thus, the opening of the work (Figure 1) starts with a pulse of a crotchet or quarter-note $(1 / 4)$. The extremely loud, short, and fast gesture on the wood percussion (asterisk) provides contrast and effectively creates a stop-time effect. The deep bass-drum then takes over again (solid line) at the same speed as before (crotchet), but soon slows down to three pulses to a bar, effectively a pulse of a minim triplet. The American terminology is more useful here, as it can be extended accordingly: the pulse of a quarter-note changes to a pulse of a 'third-note' (the minim triplet), as is shown at the bottom of the $y$-axis $(1 / 3)$.

The two superposed layers of each single canon part appear to correspond to Grisey's concepts of object and process. These, further correspond to extensive and intensive conceptions of time (as the former occupies no time at all and the latter relies fundamentally on temporality). As I showed earlier, object and process are chiastically related through the function of time. Le noir exemplifies this chiastic temporality in transforming object to process. As the music unfolds, the two layers of activity within each single part proceed as follows: on the one layer, the pulsations gradually speed up or slow down, effectuating a process based on intensities (speeds, dynamics); ${ }^{.4}$ on the other layer, the temporal intervals between consecutive objects decreases consistently, so these objects gradually become to be perceived as part of a process. Thus, the second layer effectively converts extensities to intensities. I will term these layers as intensive process and emergent process; the latter is so because when all percussionists join in, the process takes the form of spatial movement that gives rise to intensities of speed (1A) or slowness (2A). These two

54 In section 1A, dynamics gradually increase overall, but of $2 \mathrm{~A}$, each percussionist performs a series ofcrescendodecrescendo lines. This analysis focuses on perceivable tempi, although in the former section dynamics coincide with the overall increase of tempo. 
intensities, as well as those of acceleration, deceleration, physical space movement, dynamics, volume, timbre, are all virtual aspects of the work (in the sense that they exist independently of it). The scope of this analysis is to explore the ways in which the work's actuality relates to these. The emergent process effectuates a kind of intensification, a turning of extensive time into intensive, and comprises one significant aspect of such actualisation. Note that intensification does not necessarily imply acceleration, or increase of dynamics. Rather, it should be thought more fundamentally as the actualization of the virtual properties in each of these two layers, which may, and indeed do, imply decrease of speed as an intensity in its own right. I will come back to this point at the concluding remarks. As each percussionist performs both processes (intensive and emergent) one on the membranophones and the other on the idiophones, I will study them separately before I consider the canon, which is effectuated when the other percussionists enter successively.

\section{Intensive Process}

These pulsations of this process are effective perceivable tempi, so I will be using the terms 'pulse' and 'tempo' interchangeably. Interestingly, the opening beat of the work consists in a crotchet rest in a 5/4 bar immediately followed by a series of $4 / 4$ bars; which denotes that the pulsations are not meant to be perceived or performed with a metric downbeat. The metric arrangement of the work only serves to accommodate the length of structures and further practicalities, such as counting and synchronisation between percussionists. Figure 1, a mapping of the single part in section 1A, provides additional information on three distinct stages. With one exception, changes always take place between adjacent tempi, which denotes an overall high degree of continuity (pre-audibility). At the beginning, the percussionist alternates between the quarter- and third-note pulses, before jumping to the fifth-note pulse - the one exception. ${ }^{55}$ This is labeled 'Phase $a$ ' where the degree of

55 Note that at the opening of the work percussionist 1 performs these with occasional rests, not shown in the graph of Figure 1, but shown in the graph of Figure 3. As with several other minor discrepancies in the application of the canon, there seems to be no rigorous process related to such rests. 
pre-audibility is at its lowest. On Grisey's continuum of temporal categories on the skeleton of time, this phase would be close to the periodic category, as there is no pattern to suggest any speeding up or slowing down, but alternates mainly between two tempi. From this point onwards changes of pulse are sequential. In each unit of the sequence in phase $b$ the tempo moves up two steps before reverting one down for the next unit. Phase $c$ consists in shorter units where the tempo moves up one step only to repeat this immediately, until it reaches the highest pulse of a 'twentieth-note' (five quaver quintuplets to a bar). Both phases $b$ and $c$ are then in the continuous-dynamic category. Thus from the non-directional phase $a$, the single part of this tempo canon passes on to two tempo sequences. Therefore, it is phases $b$ and $c$ that would cause the tempo canon to emerge, the latter being an accelerated version of the former. Acceleration is thus built into the single part itself.

The same analysis can be carried out for the pulsations of section 2A (Figure 2). Here the first phase consists in a single pulse of $1 / 64$ (clearly in the periodic category). Phases $b, c$, and $d$ consist in sequences that gradually slow down the rate of deceleration (continuous-dynamic). Reducing the rate of deceleration does not imply a feeling of 'less deceleration' but corresponds to Grisey's application of pulsations based on the simple scale ratio of Table 2 (third row), where, as with section 1A (Figure 1) but to a greater extent, the differences between each pulse cycle through the same four ratios. As shown in the fourth row ('Pulse'), this simple ratio scale from 3 to 8 determines the pulsations (with the ratio 3:4 being employed only at the opening of $1 \mathrm{~A}$ and not in 2A). ${ }^{56}$ The application of the same logic in both sections, further confirms Deleuze's conviction that slowness is itself an intensity (and not the negative of speed). We see that in both sections $1 \mathrm{~A}$ and

56 Note that the layout of these pulsations does not associate them with each percussionist (as does for the tempo markings); nor does the table suggest that all pulsations are performed by each percussionist. The lower part of Table 2 merely lists all pulsations included in the two sections, and lays them out according to the ratio scale. Only pulses from the 'third-note' to the hemidemisemiquaver $\left({ }^{1} / 64\right)$ are scored as such. These are nominal and do not factor in the tempo markings for each percussionist - I will deduce the perceivable tempo for each pulsation of each percussionist in the following section. Table 2 includes faster ones as the logical extension of the linear ratio scale, up to $1 / 192$ which is where the effective pulsations almost reach up to (taking into account tempo markings). 
$2 \mathrm{~A}$, each of the phases in the process of speeding up or slowing down provides further acceleration or deceleration. Thus, each phase adds an additional differential quality: if an accelerando or a rallentando is a difference in speed, each further phase provides a difference in acceleration/deceleration itself - that is, a kind of 'second-degree' speeding-up/slowing-down. This of course relates to a known discovery by the spectralists, that acceleration or deceleration is perceived not via linear, but via exponential/logarithmic processes.$^{57}$ In terms of intensities, we could say that intensification is already built in the intensive process.

\section{Emergent Process}

The objects in the single part of the emergent process extend in chronometric time and initially appear to be temporally isolated. Also, these objects rarely coincide until the end where all six parts converge, due to both the decreasing distance between consecutive objects, and the increasing tempo markings for each percussionist. As I have shown, in section 1A these are loud, short, explosive gestures on the wood percussion with a descending profile; in section $2 \mathrm{~A}$ these are diametrically opposite: soft, slow, and irregular gestures on the skin percussion. Although I consider these objects to be repetitions, they are not identical, but slightly different versions of one another, maintaining the characteristics outlined here. In 1A their rhythmic profile gets gradually longer and slower, ranging from half beat to one and a half beat (the space reserved for each is two crotchets). ${ }^{58}$ In $2 \mathrm{~A}$, the objects' profile stretches gradually from the lower membranes to include progressively higher ones; their rhythmic profile is irregular but their texture becomes gradually denser with consistent use of grace-notes; for each one of these objects the space of four crotchets is reserved. In

57 See Murail, 'Target Practice', 152.

58 Luigi Manfrin provides a list of these objects in section 1A. See Luigi Manfrin, 'Gérard Grisey: periodicità, oscillazioni e risonanze in Tempus ex machina al limite tra udibilità e inudibilità', De Musica XII (2008), $<$ http://users.unimi.it/gpiana/dm12/manfrin\%20-\%20tempus\%20ex\%20machina/tempus\%20ex\%20machina.pdf > (accessed 13 April 2017), 15. 
both cases, at the early stages, these take place in a contrasting context: the soft, slow, membranophone pulsations of $1 \mathrm{~A}$ and the loud, fast, idiophone pulsations of $2 \mathrm{~A}$. The distance between consecutive objects decreases in a continuous, but not strictly regular way. According to Baillet, these distances (measured in crotchets at the onset of each object) are derived from one of the few numeric sequences used for all durations in the work, in particular from a number sequence based on a harmonic progression of $168 / \mathrm{n}$, where $\mathrm{n}$ takes values from 3 to 8 . As shown with regard to pulsations, this simple arithmetic scale from 3 to 8 is the basis for generating the sequences for all tempi and all durations of Le Noir. ${ }^{59}$ The distances between consecutive objects in both sections, measured in crotchets are:

\begin{tabular}{|c|c|c|c|c|}
\hline \multicolumn{4}{|c|}{ Section 1A } & Section $2 \mathrm{~A}$ \\
\hline & & 56 & & 84685648 \\
\hline 42 & 34 & 28 & 24 & 42342824 \\
\hline 21 & 17 & 14 & 12 & 21171412 \\
\hline 10.5 & 8.5 & 7 & 5.5 & $\begin{array}{llll}10 & 9 & 7 & 6\end{array}$ \\
\hline 5.5 & 4.5 & 3.5 & 5 & $\begin{array}{llll}5 & 4 & 4 & 3\end{array}$ \\
\hline
\end{tabular}

which are slightly modified version of the original sequence (where each row is theoretically derived by halving the values of the one above).

\section{Tempo Markings}

The work relies on a crucial distinction between tempo marking and perceivable tempo. Tempo markings in Grisey are not meant to be perceived as such, but are means to contracting or

59 In section $1 \mathrm{~A}$ each new percussionist enters at one stage later into the sequence (thus having one object less than its preceding percussionist). Also, different percussionists have slightly modified versions of this sequence. See Baillet, Gérard Grisey, 168-9. 
expanding processes and objects: 'The tempi [i.e. tempo markings] in my music seldom have a structural value. More often, they serve to compress or expand a musical sequence, and it is therefore the total duration of this sequence which is structurally important, and not the unit of measurement'. However, he goes on to say that (with regard to the processes analysed here) tempo markings may be used to structure the overall process due to their relationships; thus, they 'become the basis of an elementary periodic structure [and] take on a phenomenological value' ${ }^{60}$ In other words, in the two double canons, the perceivable tempi are provided by the pulsations (membranophones in 1A, idiophones in 2A), which are in turn affected by each percussionist's own tempo marking. These markings are derived from a from a similar process as that mentioned in the previous section $^{61}$ and rely on the same arithmetic progression. In both sections there is a constant difference between each tempo marking: 15 for $1 \mathrm{~A}$ and 13.75 for $2 \mathrm{~A} .{ }^{62}$ In Table 2 the top two rows show the metronome markings for each percussionist (and how these correspond to the aforementioned ratio scale).

\section{Canons}

The difference in tempo markings is a cause for the low degree of pre-audibility at the initial stages of the canons. As shown in Table 1, these two canons start with a solo that evolves into heterophony. Figures 3 and 4 show the canons in their entirety. ${ }^{63}$ These use an additional dimension, that of physical space; the six percussion parts are colour-coded according to the colour spectrum: when the colour gets gradually warmer or colder there is directional movement in physical space.

60 Grisey, 'Tempus ex machina', 242.

61 See Baillet,Gérard Grisey, 169.

62 All metronome markings are given at the crotchet. In $2 \mathrm{~A}$ the first tempo marking was reduced in order to fit the rate of the Vela pulsar (see Baillet, Gérard Grisey, 174), which is $1 / 44$ at $\mathrm{MM}$ crotchet $=60$, as shown on the score; subsequent tempo markings were reduced accordingly.

63 As with the aforementioned non-systematic application of rests, the application of the canon is not always entirely strict; for example, in the $1^{\text {st }}$ percussionist's entry into phase $c$, the first unit of the sequence is repeated. 
Due to the complexity of sound-events, especially at the early stages when the parts still seem independent, these canons are of the 'statistical acceleration/deceleration' type of the discontinuousdynamic category, as their change of overall perceived tempo is effected according to a clear macroscopic vector. In other words, they are examples of the 'positively or negatively oriented discontinuity' during which the listener's attention may be drawn away from the overall dynamism to the local qualities:

The Gestalt of a temporal sequence thus determined remains orientated vectorially whatever the statistical meanderings. Excluded from the global form, pure chance is thus limited, held back in some way; the general dynamism takes over. It does not follow, however, that our perception is automatically able to work out the orientation of such a sequence. If the curve is too long, or if the ambitus of the differences in durations or in rhythmic densities is too large, we will pay greater attention to the surprise of the moment than to the actual sense of the sequence. Excessive discontinuity and excessive information focus our attention on the present moment, prevent us from taking any kind of retrospective view, and put a mute in our memory! ${ }^{64}$

Clearly, the canon of section $1 \mathrm{~A}$ is of the less continuous kind, as its curve takes longer to follow the vectorial dynamism of acceleration. The canon of $2 \mathrm{~A}$ is also less continuous at the beginning, due to the entry of the percussionists before their actual canon parts; this is shown in Figure 4 by dotted lines, which represent the percussionists' entry at near-unison at a pulse of $1 / 64$, on the gong, tam-tams, or Chinese cymbal (taking into account tempo markings), to join the rhythm of the Vela pulsar. ${ }^{65}$

64 Grisey, 'Tempus ex machina', 253.

65 At Fig. 55 the Vela enters with a pulse of $1 / 44$ at quaver $=120$; the percussion enter at Fig. 57 with a pulse of $1 / 64$ at crotchet $=41.25$; these two pulsations are the same upon conversion. 
The lower part of figures 3 and 4 indicate the phase-entries for each percussionist; these entries take place in regular succession, that is, the $1^{\text {st }}$ percussionist is the first to enter into a new phase, and the $6^{\text {th }}$ is the last. In $1 \mathrm{~A}$ (Figure 3 ) the canon emerges in two stages:

i. The first stage consists of the entering into phase $b$ of percussionists 4 to 6 . At Fig. 11 physical space movement coincides for the first time with the entry into a new phase (prior to this, physical space movement was interrupted by the entry of the $6^{\text {th }}$ percussionist into phase $a$ ). This is when the $4^{\text {th }}$ percussionist enters into phase $b$, followed by the $5^{\text {th }}$ and $6^{\text {th }}$. This might not be audible very clearly, due to the aforementioned local statistical meanderings; however, an overall sense of acceleration is provided by five percussionists, three of which doing so successively, until the $6^{\text {th }}$ enters into phase $b$ (which is the first sequential phase), at the end of this stage. ${ }^{66}$

ii. The second stage comprises the entering into phase $c$ of all percussionists. Although in the previous stage, physical space movement coincided with the entering into the first phase of acceleration $(b)$, that concerned more the intensive process, while the objects of the emergent process still appeared statistical. At this stage of a second degree of acceleration, physical space movement is clearly more audible as the objects gradually converge temporally, up to Fig. 14 where they finally coincide at rhythmic unison. It is here when the emergent process has transformed extensities to intensities; and where objects have transformed into processes, not by time-stretching, but by accelerating the rate of events. This is not only due to the aforementioned second-degree accelerando built into the individual parts, but also due subsuming both processes into an increasing circular space movement; if I may borrow the title of another Grisey work, this is a case of a spatiotemporal vortex.

66 The apparent slowing-down ofentry into phase $b$ of the $6^{\text {th }}$ percussionist, as is obvious in Figure 3 , does not imply a systematic application, but seems to be the result of non-rigorous application of the canon. 
In section $2 \mathrm{~A}$, the process is more continuous relative to $1 \mathrm{~A}$. Although the local statistical meanderings are still operative for the reason mentioned, the overall shape of the canon is closer to the 'geometric progression' type.$^{67}$ After the initial near-unison (phase $a$ ), the percussionists enter to set off a process of deceleration, which itself is more continuous than the earlier canon. The canon's three phases, $b, c$, and $d$, are all sequential; further, the passing from one phase to the next seems less noticeable (see Figures 2 and 4). However, a similar process of canon emergence is evident here:

i. The first uninterrupted entry into a new phase by four percussionists takes place at the beginning of phase $c$ between Figs. 72 and 75. Therefore, like phase $b$ in $1 \mathrm{~A}$, it is in phase $c$ when the canon starts to emerge.

ii. The second stage of canon emergence is of course the entering into phase $d$ at Fig. 77, into which five percussionists enter successively. Due to the overall accelerating logic, via which this deceleration is achieved the canon is gradually taking more concrete shape. As with the earlier canon, this canon is all the more evident due to the increasingly intense spatiotemporal vortex.

What is interesting about the double canon at $2 \mathrm{~A}$ is that even though the overall effect is that of deceleration, each successive percussionist enters at a higher intensity, that is, effective tempo; this increase of tempo also causes the successive phase entries, from $a$ through to $d$, to accelerate. Thus, the overall deceleration incorporates an accelerating logic. This acceleration is itself an intensity that contributes, paradoxically, to the composite intensity of deceleration of this canon. As with Deleuze's conception of difference, combining the two seemingly opposite intensities results not in weakening the overall effect, but intensifying it. This is precisely because the two composite intensities of acceleration and deceleration are not reciprocally negative, but each contributes in complex ways to the otherwise simple application of the canon in section $2 \mathrm{~A}$.

67 Grisey, 'Tempus ex machina', 248. 


\section{Asymmetrical Balance}

Sections $1 \mathrm{~A}$ and $2 \mathrm{~A}$ of Le Noir, comprise unique examples of rendering intensities audible. This is theorized by Deleuze as rendering-audible of inaudible forces, paraphrasing Paul Klee's 'renderingvisible'. ${ }^{68}$ I further paraphrase here, substituting forces by intensities, conceived as pure differences that effectuate a pure becoming. This becoming is defined as 'a process all in its own right and it varies, not in relation to others according to logical or empirical relations, but in terms of intrinsic intensity, more or less slowness, for instance (which does not imply less or more speed) ${ }^{69}$ Speeding-up is not simply the opposite of slowing-down (this would be true if intensity were a 'metrical' difference in degree); it is for this reason that their combination in musically meaningful ways is made possible. In this sense, the two sections are not reflected or complementary forms of one another. If that were the case, in $2 \mathrm{~A}$ all percussionists would perhaps start playing tutti and gradually diverge and drop out due to their different tempi (thus moving from heterophony to solo). But Grisey relies on the accelerated convergence of percussionists for both sections, which enables physical movement, itself an intrinsic intensity achieved gradually. Both sections rely on the combination of intensities that creates a complex web of speeds and slownesses, of accelerations and decelerations. This is, I believe, audibly sensed by the listener. The paradox of section $2 \mathrm{~A}$, a deceleration that incorporates accelerating logic, is a manifestation of the multiple time arrows that give rise to what Grisey called the 'expectancy in the void of the present', a kind temporal suspension caused when the music's time arrow contradicts that of the listener's. ${ }^{70}$ As I hope this analysis has shown, the different time arrows already exist as different intensities (on different

68 See Gilles DeleuzeFrancis Bacon: the logic of sensation, trans. Daniel W. Smith (London: Continuum, 2003), 56ff. The 'audible' analogy in music should not be taken as limiting and one should consider its inter-sensory aspects, as noted above in Nancy's conception of music — indeed all art—as syn-aesthetic.

69 See James Williams,Gilles Deleuze’s Philosophy of Time: A Critical Introduction and Guide (Edinburgh: Edinburgh University Press, 2011), 140; italics added. 
levels) within the work itself; the void of the present is effected by conflicting time arrows that are neither complementary nor symmetrically related.

Each speed or slowness, speeding-up or slowing-down, contracting or time-stretching, make up a multiple of intensities, given as a composite experience that is both virtual and actual. These two aspects, always bound together, exist in a kind of asymmetrical balance. The intensities of speed and slowness are here virtual in the sense that they are independent of the their actual sonorous manifestation. Their actualization is a composed deployment of both virtual and actual aspects (the becoming actual of the virtual). As Williams notes, 'for Deleuze it only really makes sense to speak of events as, at the same time, virtual and actual'. ${ }^{71}$ An analysis of an event must rely on the ways in which its actual aspects 'touch' upon the virtual in order to emphasize some over others. Therefore, what makes an event unique is not its actual characteristics, but their relation to its virtual aspects. Uniqueness can only be achieved when evoking pure differences that do not allow negation or complementarity — hence the asymmetrical balance between actual and virtual.

In Le Noir Grisey seems to have responded to this reality concretely in the way he employed the processes discussed above. As the processes are not symmetrically related, the two sections are not mirror forms of each other. This is evident in the canons as the asymmetric interweaving of the two processes within each one of the six parts of each canon: one intensive, based on speeds and slownesses that accelerate and decelerate; the other emergent, based on objects that eventually emerge as part of a process. One is based on pure differences and the other on turning objects into processes by time-contraction (as both rely on acceleration). The two relate to the virtual aspects of the music in different ways; the former directly so, and the latter by being subsumed into the intensive process, with which it shares the logic of acceleration, thus being secondary (albeit essential). We see that, although there is symmetry in the chiastic relationship between object and process, their deployment as analysed here is asymmetric. Both of these are given as a composite of virtual and actual in asymmetrical balance, which underlies the heterogeneity of spectral time: the 71 Cf. Williams, Gilles Deleuze's Difference and Repetition, 9. 
two kinds of time, one experiential, the other chronometric; one virtual the other actual; one heterogenous the other homogeneous. This is a higher degree of heterogeneity. Given the radical complexity of the matter, a definitive account of spectral time here would be unwise. But, as I hope this article has shown, spectral time emerges as the experience of a heterogenous temporality, that relies neither on measurable nor on experiential time alone, but on all their degrees of difference. 


\section{Bibliography}

Baillet, Jérôme. 'Gérard Grisey', trans. Azizeh Azodi, in Gérard Grisey: Catalogue of the works. Paris: Ricordi,1998, 8-12.

Baillet, Jérôme. Gérard Grisey. Fondements d'une écriture. Paris; Montréal: L'Harmattan, 2000.

Bergson, Henri. Time and free will: an essay on the immediate data of consciousness, trans. F.L. Pogson. Mineola, N.Y.: Dover Publications, 2001.

Boulez, Pierre. Boulez on Music Today, trans. Susan Bradshaw and Richard Rodney Bennett.

London: Faber \& Faber, 1971.

Boulez, Pierre. Orientations: Collected Writings, ed. Jean-Jacques Nattiez, trans. Martin Cooper. London; Boston: Faber \& Faber, 1986.

Bundler, David. 'Interview with Gerard Grisey'. 20th-Century Music 3 (1996),

$<$ http://www.angelfire.com/music2/davidbundler/grisey.html $>$ (accessed 13 April 2017).

Campbell, Edward. Music after Deleuze. London: Bloomsbury Academic, 2013.

Deleuze, Gilles. Bergsonism. New York: Zone Books, 1991.

Deleuze, Gilles. Difference and repetition, trans. Paul Patton. London: Athlone, 1994. 
Deleuze, Gilles. Francis Bacon: the logic of sensation, trans. Daniel W. Smith. London:

Continuum, 2003.

Exarchos, Dimitris. 'Temporality in Xenakis and Ferneyhough'. JMM: The Journal of Music and Meaning 13 (2016), 60-91.

$<$ http://musicandmeaning.net/articles/JMM13/DimitrisExarchosJMM13.pdf $>$ (accessed 13 April 2017).

Ferneyhough, Brian. Collected Writings, ed. James Boros \& Richard Toop. Amsterdam: Harwood Academic Publishers, 1995.

Grisey, Gérard. 'La musique, le devenir des sons', in Algorithmus, Klang, Natur: Abkehr vom Materialdenken? Mainz: Schott, 1984, 16-23.

Grisey, Gérard. 'Tempus ex machina: A composer's reflections on musical time'. Contemporary Music Review 2/1 (1987), 239-75.

Grisey, Gérard. Le Noir de l'Étoile, pour six percussionistes, band magnétique et retransmission in situ de signaux astronomiques. Milano: Universal Music Publishing Ricordi, 1990.

Grisey, Gérard. 'Did you say Spectral?'. Contemporary Music Review 19/3 (2000), 1-3.

Grisey, Gérard. Le Noir de l'Étoile. Les Percussions de Strasbourg. CD, Universal, MFA 476 1052, 2004. 
Haselböck, Lukas. Gérard Grisey: Unhörbares hörbar machen. Freiburg: Rombach Verlag, 2009.

Hennessy, Jeffrey J. 'Beneath the Skin of Time: Alternative Temporalities in Grisey's Prologue for Solo Viola'. Perspectives of New Music 47/2 (2009), 36-58.

Kolakowski, Leszek. Bergson. Oxford; New York: Oxford University Press, 1985.

Lebaron, Anne and Denys Bouliane. 'Darmstadt 1980'. Perspectives of New Music 19/1-2 (19801981), 420-41.

Lochhead, Judy. Reconceiving Structure in Contemporary Music: New Tools in Music Theory and Analysis. New York: Routledge, 2016.

Luminet, Jean-Pierre. 'Le Noir de l'étoile: La musique des pulsars', in Le temps de l'écoute: Gérard Grisey, ou la beauté des ombres sonores, ed. Danielle Cohen-Levinas. Paris; Budapest; Torino: L'Harmattan, 2004, 159-82.

Manfrin, Luigi and Marcello Piras. 'Spettromorfologia, Durata et Differanza: La presenza di Bergson nel pensiero musicale di Gérard Grisey'. Rivista Italiana di Musicologia 38/1 (2003), 75117.

Manfrin, Luigi. 'L'immagine spettrale del suono e l'incarnazione del tempo allo stato puro. La teoria della forma musicale negli scritti di Gérard Grisey’. De Musica VIII (2004), <users.unimi.it/gpiana/dm8/manfrin/grisey.zip> (accessed 13 April 2017). 
Manfrin, Luigi. 'Gérard Grisey: periodicità, oscillazioni e risonanze in Tempus ex machina al limite tra udibilità e inudibilità'. De Musica XII (2008). <http://users.unimi.it/gpiana/dm12/manfrin\%20\%20tempus\%20ex\%20machina/tempus\%20ex\%20machina.pdf> (accessed 13 April 2017).

Moore, A. W. The evolution of modern metaphysics: Making sense of things. Cambridge; New York: Cambridge University Press, 2012.

Murail, Tristan. 'Target Practice', trans. Joshua Cody. Contemporary Music Review 24/2-3 (2005), $149-71$.

Nancy, Jean-Luc. The Muses, trans. Peggy Kamuf. Stanford, Calif.: Stanford University Press, 1996.

Nancy, Jean-Luc. Listening, trans. Charlotte Mandell. New York: Fordham University Press, 2007.

Pustijanac, Ingrid. 'Time's arrow in spectral music'. Nuove Musiche 1 (2016), 141-56.

Williams, James. Gilles Deleuze's Philosophy of Time: A Critical Introduction and Guide. Edinburgh: Edinburgh University Press, 2011.

Williams, James. Gilles Deleuze's Difference and Repetition: A Critical Introduction and Guide, 2nd edn. Edinburgh: Edinburgh University Press, 2013.

Xenakis, Iannis. Formalized Music: Thought and Mathematics in Composition, ed. Sharon Kanach, revised edn. Stuyvesant, New York: Pendragon Press, 1992. 
Xenakis, Iannis. Kéleütha (Ecrits), ed. Alain Galliari, preface by Benoît Gibson. Paris: L'Arche, 1994. 